\title{
Sight or smell? Behavioural and heart rate responses in subordinate rainbow trout exposed to cues from dominant fish
}

Johan Höjesjö, Michael Axelsson, Ronja Dahy, Lena Gustavsson, Jörgen I Johnsson

Many animals, including fish, can utilize both vision and the chemical senses in intraspecific communication. However, the relative influence of these sensory modalities on behavioral and physiological responses in social interactions is not well understood. The aim of this study was therefore to investigate the relative effects of visual and chemical stimuli from dominant individuals on the behavioral and physiological responses of subordinate rainbow trout (Oncorhynchus mykiss). External electrodes were used to detect ECG signals from free-swimming fish. This method allowed the simultaneous recording of behavioral and physiological responses, and possible sex differences in these responses were also investigated. The results suggest that, in this context, visual cues are more important than chemical cues in settling the social hierarchy in rainbow trout because a combination of chemical and visual exposure generally yielded a response in focal fish that was similar to the response elicited by visual exposure alone. Both activity and physiological responses were most pronounced during the first ten seconds after exposure, with subordinate fish moving closer to the dominant, accompanied by a strong bradycardic response. Furthermore, females acted more boldly and moved closer to the dominant fish than males, but here the effect of the modes was additive, with a stronger effect of the combined visual and chemical exposure. Overall, the extra information furnished to the fish in the form of chemical cues did not change either the behavioral or the physiological response. This result suggests that visual cues are more important than chemically mediated ones for social communication and individual recognition in rainbow trout. 
Sight or smell? Behavioral and heart rate responses in

Höjesjö, J., Axelsson, M., Dahy, R.,

Gustavsson, L. \& Johnsson, J.I. 


\section{Abstract}

Many animals, including fish, can utilize both vision and the chemical senses in intra-specific communication. However, the relative influence of these sensory modalities on behavioral and physiological responses in social interactions is not well understood. The aim of this study was therefore to investigate the relative effects of visual and chemical stimuli from dominant individuals on the behavioral and physiological responses of subordinate rainbow trout (Oncorhynchus mykiss). External electrodes were used to detect ECG signals from freeswimming fish. This method allowed the simultaneous recording of behavioral and physiological responses, and possible sex differences in these responses were also investigated. The results suggest that, in this context, visual cues are more important than chemical cues in settling the social hierarchy in rainbow trout because a combination of chemical and visual exposure generally yielded a response in focal fish that was similar to the response elicited by visual exposure alone. Both activity and physiological responses were most pronounced during the first ten seconds after exposure, with subordinate fish moving closer to the dominant, accompanied by a strong bradycardic response. Furthermore, females acted more boldly and moved closer to the dominant fish than males, but here the effect of the modes was additive, with a stronger effect of the combined visual and chemical exposure. Overall, the extra information furnished to the fish in the form of chemical cues did not change either the behavioral or the physiological response. This result suggests that visual cues are more important than chemically mediated ones for social communication and individual recognition in rainbow trout.

Keyword: Salmonids, Physiology, Behavioral, Communication, Heart rate, Dominance 


\section{Introduction}

An important aspect of animal communication is the ability to send and receive

information about social status (i.e., resource holding potential, defined as an individual's ability

to win or persist in a fight, Enquist and Leimar 1983,Hurd 2006, Parker 1974). This ability is

critical for reducing costs of conflicts over resources or over dominance positions in

hierarchically structured groups (Huntingford and Turner 1987). The resource holding potential

of an opponent can be inferred by assessment of status-related traits such as body size, weaponry or badges (Bradbury and Vehrencamp 1998) or by observing the opponents' success in contests against other individuals (Johnsson and Åkerman 1998; Oliveira et al. 1998). Furthermore, to

2 to be able to identify and subsequently recognize the other individual (Johnsson 1997, Höjesjö et

al. 1999). In addition, general winner and loser effects tend to conserve relative social status, as contest winners tend to continue their winning streaks, all other things being equal, whereas losers tend to go on losing (Dugatkin 1997; Schuett 1997). The communication of relative fighting ability and subsequent maintenance of social status in animal groups can be mediated by a variety of sensory modes depending on the particular animal taxon in question (Alcock 2005). Fish, the most species-rich of all vertebrate taxa, have evolved a variety of modes for communication, including visual, chemical, acoustic, mechanic and electrical sensory systems (Rosenthal and Lobel 2006). Generally, chemical cues in aquatic systems are argued to be of particular importance to mediate communication because water is an excellent medium to transmit a wide range of chemicals and, additionally, because visual cues are disrupted by light attenuation, turbidity, and/or habitat complexity (Ward \& Mehner 2010, Giske et al. 1998). 
64 Accordingly, many fishes rely on chemical cues for foraging (Webster et al. 2007), mate choice

65 (Aeschlimann et al. 2003) and migration (Hasler and Cooper 1976). Visual cues, however, may

66 be more important during the formation of stable social hierarchies within species because,

67 especially over shorter distances, visual cues might more directly reflecting an individual's

68

competitive ability and status (Höjesjö et al. 1998, Oconnor et al. 1999, 2000 ). Nevertheless, it has also been argued that chemical cues are used to recognize dominance initially and Barata et al. (2007) have demonstrated how dominant males of the Mozambique tilapia store urine and actively release it during aggressive disputes. Most likely, the urine acts as a 'dominance' pheromone to modulate aggression and thereby contribute to social stability.

Salmonid fish, the focus of this study, have excellent vision and chemical senses that are used for a multitude of important tasks. For example, young brown trout (Salmo trutta) find cryptic prey (Johnsson and Kjällman-Eriksson 2007) and avoid predators (Griffiths et al. 2004) by visual detection. Pacific salmon (Salmo salar) learn both to recognize their home river (Caprona, 1982; Quinn and Dittman 1990) and assess predation risk (Martel and Dill 1993) based on chemical cues. As in many other species, visual cues (i.e., body size) are reliable predictors of the outcome of dyadic contests in salmonids (Johnsson et al. 2006). Moreover, the finding that contest intensity decreases as opponent size differences increases in dyadic contests suggests that visual cues are used to assess fighting ability (Johnsson et al. 1999). It is not known to what extent salmonids also use chemical cues to communicate intrinsic fighting ability and social status. However, chemical cues have been found to affect aggression levels in groups of Atlantic salmon (Griffiths and Armstrong 2000).

The behavioral and physiological responses to assessment and contest situations in animals are intrinsically linked (Johnsson et al. 2006), and it is well established that threatening 
87 situations can induce cardioventilatory responses. In mammals, bradycardia (decreasing heart

rate) is associated with freezing or hiding, whereas tachycardia (increasing heart rate) is associated with flight or defense (Belkin et al. 1968, Moen et al. 1978; Smith et al. 1981; Espmark and Langvatn 1985). Furthermore, salmonids respond to predator attacks with bradycardia and flight, followed by a tachycardic response that increases the supply of oxygen to the body as part of the fight or flight response (Höjesjö et al. 1999; Johnsson et al. 2001). Furthermore, we have shown that rainbow trout bystanders react rapidly, with behavioral avoidance, to potential opponents. That these opponents later become dominant suggests that bystanders can rapidly assess the fighting ability of potential opponents (Höjesjö et al. 2007). This behavioral effect was subsequently (the following day) followed by an elevated heart rate in bystander fish exposed to dominant opponents. However, the experimental design did not allow us to tease apart the relative effects of visual and chemical stimuli on these responses, and the determination of these effects furnished the main rationale for performing this study. Accordingly, in the present study, we aim to evaluate the relative effects of visual and chemical stimuli from dominant individuals on the behavioral and physiological responses of subordinates. We also investigate whether males and females differ in this response. Such sexspecific data are presently missing, and our results could, hopefully, provide new important insights. For this purpose, dyadic contests were staged between rainbow trout (Oncorhynchus mykiss), and the winner (dominant) and loser (subordinate) were determined. Subordinate individuals were then subjected to visual and/or chemical cues from the dominant, and their behavioral and physiological (i.e., heart rate) response to these cues were recorded and compared with a control (no cues) treatment. 


\section{Methods}

111

112 The study was performed between February and April of 2007 with one-year-old (1+) hatchery-

113 reared (Antens Laxodling $\mathrm{AB}$ ) rainbow trout and approved by the Ethical Committee for Animal

114 Research in Göteborg (license 199/2002). The fish $(n=200)$ were transported from the hatchery

115 in specially designed fish transport containers (stainless steel construction, approximately $1.5 \mathrm{~m}^{3}$

116 in size with built-in aeration). The transport time was less than 40 minutes, and the density of the

117 fish in the containers complied with the Swedish regulations for transportation of fish.

118 After arrival at the Department of Biological and Environmental Sciences in Gothenburg, all fish

119 were transferred and kept in large plastic tanks $(150 \times 75 \times 75 \mathrm{~cm}, \mathrm{~h} / \mathrm{w} / \mathrm{l})$ for at least 48 hours

120 before the trials to acclimatize the animals. Food was provided ad libitum. These tanks were

121 equipped with a floating plastic cover to provide shelter and shadow, thereby reducing the

122 overall stress on the fish. All aquaria used for the experiment, as well as the acclimatization

123 tanks, were supplied with well-aerated water from the main aquarium system. This system used a

124 sand filter and a UV filter. Two types of aquaria were used in the study: "dyadic aquaria"

$125(35 \times 34 \times 64 \mathrm{~cm}, \mathrm{~h} / \mathrm{w} / \mathrm{l})$, where the social rank was determined, and "experimental aquaria"

$126(40 \times 48 \times 64 \mathrm{~cm}, \mathrm{~h} / \mathrm{w} / \mathrm{l})$, where the subordinate fish were exposed to a combinations of cues from

127 the dominant fish. Both "dyadic" and "experimental" aquaria were filled with water $\left(10^{\circ} \mathrm{C} \pm 1\right)$ to 128 an approximate depth of $20 \mathrm{~cm}$. The experimental aquaria had a flow through rate of $1.41 / \mathrm{min}$.

129 In total, seven experimental aquaria and seven dyadic aquaria were used. In addition, we used 
130 two smaller aquaria $(20 \times 24 \times 32 \mathrm{~cm} \mathrm{~h} / \mathrm{w} / \mathrm{l})$ to transfer chemical cues to the experimental aquaria

131 during the application of the chemical treatment (figure 1).

132

133

134

Dyadic contests

135

136 Trout to be used in the experiment were first anesthetized with 2-phenoxy ethanol $(0.5 \mathrm{ml} / \mathrm{l})$,

137 measured in weight and length and then transferred to the smaller "dyadic aquaria" where they

138 were allowed to settle for 24 hours. Each pair was size-matched on the basis of length $(+/-0.5$

139 $\mathrm{cm}$ ) to minimize any size-related behavior differences (Huntingford et al., 1990).This aquarium

140 was divided in two parts by placing a dark opaque sliding hatch in the middle. After 24 hours,

141 the opaque sliding hatch was carefully hoisted by pulling on a string attached to the hatch. This

142 procedure was used to minimize stress. The social rank of the two fish was then determined. The

143 contests were allowed to last for a maximum of $2 \mathrm{~h}$ and lasted, on average, $30 \mathrm{~min}$; the duration

144 of the contests ranged between 20 and $110 \mathrm{~min}$. The dominant fish was defined as the individual

145 winning more than $90 \%$ of the interactions (Höjesjö et al., 2007) and retaining its original

146 coloration (O'Connor et al., 1999). The dominant fish also spend more than $75 \%$ in the middle

147 of the aquarium (Höjesjö et al., 2007). Accordingly, we did not observe any abnormal behavior

148 or any injury (defined as visible wounds) to any of the fish during the experiments. No additional

149 refuge was given in the dyadic aquaria because the provision of a refuge would, most likely,

150 have increased the time needed to determine rank, and the subordinate fish were removed as

151 soon as the rank was settled. Hence, the fish were not exposed to more stress than was absolutely

152 needed to assess their relative social rank. After the dyadic contest, opponents were separated by 
153 lowering the hatch, and both fish were transferred to either the experimental aquarium or the

154 smaller aquarium used to collect chemical cues and left to acclimate for approximately 4 hours.

155 When placed in the experimental aquarium, the subordinate fish was transferred to the front

156 portion of the aquarium and the dominant to either the back portion of the experimental

157 aquarium or the smaller separate aquarium, depending on the treatment. For visual and

$158 \mathrm{visual} / \mathrm{chemical}$ treatment, the dominant fish (the winner) was placed in the rear section (see

159 figure 1).

Although we cannot rule out the possibility of rank reversal in this study,

161 differences in the behavior of many animals (temperament) have been described as both

162 consistent (Reale et al 2007) and repeatable (Bell et al. 2009). Hierarchies is also, usually stable

163 when they are determined since they are correlated with fighting ability which leads to the

164 phenomena that winner tends to go on winning and losers losing (Abbot \& Dill 1985, Dugatkin

$165 \&$ Druen 2004). This has also been showed in killifish, (McGhee \& Travis 2010) where males

166 showed repeatable linear dominance hierarchies. Over time, there is the possibility off course

167 during ontogenetic development that social status can change due to random effect or difference

168 in habitat quality. During the time frame in this study though, we believe that the social rank is

169 set and stable.

170

Visual and chemical exposure

172

173 The experimental aquarium was divided into two parts, with sealed, transparent Plexiglas in the

174 middle of the aquarium. The Plexiglas divider allowed no water to circulate between the two

175 sections. In addition, an opaque sliding hatch next to the transparent Plexiglas prevented the fish 
176 from seeing each other. Strings were attached to the top of the opaque sliding hatches, allowing

177 them to be carefully hoisted upward and downward without stressing the fish. The subordinate,

178 our focal fish, was placed in the front section (figure 1) and the dominant placed in the back

179 section. The placement of the front and back sections alternated between the left- and right-hand

180 sides of the experimental aquarium. The dominant fish could also be placed in one of the smaller

181 aquaria if only the effect of chemical exposure were being tested.

182

The fish were chemically isolated from each other by a separate in- and outflow of

183 water in each section. A silicon tube connected to a peristaltic pump (built to order by RS

184 Components) was attached to the aquarium, allowing water from various sources to be pumped

$185(120 \mathrm{ml} / \mathrm{min})$ into the compartment holding of the subordinate individual. The water could be

186 pumped from the section containing the dominant fish or from an aquarium containing no fish,

187 depending on the treatment. The section with the focal fish (subordinate) also had an electrode

188 cage (see details below) positioned in that section, allowing non-invasive measurements of the

189 heart rate of the fish (Höjesjö et al. 2007; Goodman and Weinberger 1971, Altimiras \& Larsen

190 2000). Hence, by having the two fish completely chemically isolated from each other, we could

191 use the hatch with only visual exposure and/ or in combination with a separate chemical

192 exposure. The following four treatments were used:

193 1) Visual exposure, 2) Chemical exposure, 3) Visual and chemical exposure, 4) Control with

194 only exposure of water and the sight of an empty compartment to control for any effect of

195 disturbance during the actual procedure (figure 1).

196

To avoid disturbing the fish, we observed them through a hole in a plastic cover for

197

two minutes before and five minutes after the opaque sliding hatch was hoisted and/or the

198 addition from the tube with chemical cues/fresh water. The section containing the focal fish was 
199

200

201

202

203

204

205

206

207

208

209

210

211

212

213

214

215

216

217

218

219

220

221

divided into nine horizontal, virtually equally sized subsections (1-9) according to a onedimensional coordinate system, with subsection nine being situated in front of the tank closest to the dominant fish. An index was then calculated based on the position of the focal fish. A greater index value corresponded to a shorter distance relative to the experimental tank occupied by the dominant individual. Activity was also observed and scored using the following index: $1=$ Holding bottom (e.g., some part of the fish touching the bottom); 2 = Holding low; $3=$ Holding high (the majority of the fish positioned in the upper half of the water column); and $4=$

Swimming.) The position and activity of the fish were recorded every $10 \mathrm{~s}$ and used to assess the change in movement and activity over time when exposed to a dominant individual. To examine any effects of habituation, the responses were recorded during three subsequent observations at approximately $4 \mathrm{~h}$ (Obs. 1), $6 \mathrm{~h}$ (Obs. 2) and $28 \mathrm{~h}$ (Obs. 3) after the rank was settled.

In total, we tested 196 (98 pairs) fish, but only fish that could be ranked clearly were used in the study. The result was that a total of 83 subordinate fish were exposed to either visual cues $(n=23)$ chemical cues $(n=20)$, visual and chemical cues $(n=21)$ or controls $(n=19)$. The order of the treatments was randomized, and all fish were tested only once. After the last observation, all focal fish were euthanized with an overdose of 2-phenoxyethanol and a lethal blow to the head, weighed and sexed by examination of the gonads. Dominant fish were not killed, and no data are, therefore, available on their sex.

\section{Heart rate monitoring}

Essentially the same setup as in Höjesjö et al. $(1999,2007)$ was used in the present study. In short, the setup consists of stainless steel electrodes for detecting bioelectric potentials in the 
222 water generated by the active muscles of the fish. From the raw signal, the ECG can then be

223 separated by careful filtering. A grid placed on the bottom of the chamber acts as one of the

224 electrodes, and a rectangular cage of fine stainless steel wires ( $2 \mathrm{~mm}$ diameter) placed

225 immediately below the water surface constitutes the other electrode (Höjesjö et al. 2007). A

226 common electric ground electrode bar is placed in the surrounding water. The fish could move

227 freely between the two electrodes and the electric ground electrode bar without noticeably

228 affecting the quality of the signal. The raw signals were amplified using four BIO Amplifiers

229 (model ML136, ADInstruments, Castle Hill, Australia). All recordings were saved at a frequency

230 of $200 \mathrm{~Hz}$ in the EEG mode of the BIO Amplifier, which was pre-set to the following

231 configuration: range: EEG mode, $1 \mathrm{mV}$; low-pass filter: $120 \mathrm{~Hz}$; high-pass filter: $1 \mathrm{~s} ; 50 \mathrm{~Hz}$

232 notch filter activated. The signals from the BIO Amplifiers were then passed to a PowerLab 8/30

233 system (ADInstruments, Castle Hill, Australia), and data were collected on a PC with

234 ADInstruments acquisition software LabChartTM 7 Pro v7.3.7. In LabChart, the signal was

235 further filtered and processed off-line to separate the electrocardiogram (ECG) signal from other

236 muscular activity, resulting in data on heart rate over time (average beat $\mathrm{min}^{-1}$ during $10 \mathrm{~s}$

237 intervals based on the time between beats ).

238

239 Data analysis

240 For the behavioral data, to focus on the event of exposure, ten $10 \mathrm{~s}$ periods before the opaque

241 sliding hatch was hoisted and ten $10 \mathrm{~s}$ periods after the opaque sliding hatch was hoisted were

242 analyzed (a total of $200 \mathrm{~s}$ of data). The average heart rate for every $10 \mathrm{~s}$ period was calculated

243 and synchronized with the behavioral data. However, because the change in heart rate is most

244 likely a more rapid response (see Höjesjö et al 2007 and references within), we only used five 10 
$245 \mathrm{~s}$ intervals before and five $10 \mathrm{~s}$ intervals after the exposure for analyses. The three dependent

246 variables, e.g., activity, position and heart rate, were all normally distributed. Therefore, separate

247 repeated measures analyses of covariance (Systat 11, Richmond, CA, U.S.A.) were used with

248 time (the 20 time periods for the behavioral data and 10 time periods for the heart rate data) as

249 the repeated measures factor, treatment (chemical, visual, chemical + visual, control) and sex

250 (males and females) as independent class variables and weight (g) as a continuous covariate.

251 Interactions between time and treatment, as well as between sex and treatment, were initially

252 included in the model but were removed using a stepwise procedure if not significant.

$253($ Activity $/$ Position $/$ Heart $=$ Time + Treatment + Sex + Weight + Time $\mathrm{x}$ Treatment + Sex $x$

254 Treatmnet) To clarify the presentation of the results, only $\mathrm{p}$ values less than 0.10 are presented.

255

256

257

258

259

260

261

262

263

264

265

266

267

268

269

\section{Results}

Overall, 83 fish (average size; $23.3 \mathrm{~cm} \pm 2.8 \mathrm{stdev}, 142.7 \mathrm{~g} \pm 47.8 \mathrm{stdev}$ ) were analyzed in the study in terms of behavioral responses (activity and position). These 83 fish comprised 45 males and 36 females (and 2 fish whose sex could not be determined), evenly distributed among treatments (Control: 8 female, 10 males; Chemical: 7 female, 13 males; Visual: 12 female, 11 male; Chemical + Visual: 9 female, 11 males). For heart rate measurements, all fish from which no signal could be accurately filtered were removed, leaving 42 individuals to be analyzed for HR (Control: 3 female, 7 males; Chemical: 5 female, 6 males; Visual: 6 female, 4 male; Chemical + Visual: 5 female, 6 males).). There were no differences in size among treatment groups or between sexes ( $>0.1$ both cases). 
Position

272

273

274

275

276

277

278

280

281

282

283

284

285

286

287

288

289

290

291

292 The overall activity did not change over time for any of the three observations $(p>0.1$ exposure 293

At the first observation, there was a significant interaction between time and treatment

$\left(\mathrm{F}_{57,1368}=1.40, \mathrm{p}=0.028\right.$; figure $\left.2 \mathrm{a}\right)$. The reason for this interaction was that only visual or a combination of visual/chemical cues caused the focal fish to move closer to the dominant fish, whereas control and chemical cues did not cause any change in position. At the second observation, all fish moved closer to the dominant fish regardless of treatment $\left(\mathrm{F}_{19,1368}=1.82\right.$, $p=0.017$, figure $2 b$ ). Neither a significant effect of treatment nor any interaction could be detected at the third observation. Furthermore, there was no difference in position due to weight or length.

There were also differences between the sexes; regardless of time and treatment, females tended to be positioned closer to the opaque sliding hatch than males during the first $\left(F_{3,72}=2.21, p=0.094\right)$ and significantly closer during the second exposure $\left(F_{1,72}=4.24, p=0.043\right.$, position index; $4.14 \pm 0.23 \mathrm{SE}$ for females and $3.42 \pm 0.23 \mathrm{SE}$ for males ). Furthermore, for the second observation, it was obvious from the separate results from the four treatments that only females in the combined chemical/visual exposures increased their position indexes, i.e., moved closer to the dominant fish (Friedman $\mathrm{p}<0.01$, Friedman test statistic $=50.20$ ), whereas males did not (figure 3).

\section{Activity} 1) even if there was a tendency for activity to differ among treatments over time on the second 
$294\left(\mathrm{~F}_{57,1368}=1.288, \mathrm{p}=0.076\right.$, figure $\left.4 \mathrm{~b}\right)$ and third $\left(\mathrm{F}_{57,1368}=1.324, \mathrm{p}=0.056\right.$, figure $\left.4 \mathrm{c}\right)$ observation. At

295 the second observation, this result most likely occurred because the fish in the control treatment

296 increased their activity, whereas the fish from the other treatment groups remained at a lower

297 activity level (figure 4b). Similarly, at the third observation, the fish in the chemical/visual

298 treatment tended to decrease their activity after exposure, whereas the fish in the other treatments

299 appeared to increase their activity (figure 4c). In addition, treatment tended to have a general

300 effect on activity at the third observation $\left(\mathrm{F}_{3,72}=2.29, \mathrm{p}=0.085\right)$, whereas fish in the

301 chemical/visual treatment appeared to have a lower activity level (figure $4 \mathrm{c}$ ).

302

There were no effects of sex during the first two observations, but there was a

303 significant interaction between sex and treatment at the third observation $\left(\mathrm{F}_{3,72}=9.93, \mathrm{p}=0.031\right)$,

304 when females exposed to chemical/visual cues remained at a relatively low activity level

305 (average activity index after exposure $1.7 \pm 0.18$ ) compared with female fish exposed to any of

306 the other three treatments (activity index for females exposed to visual cues: $2.25 \pm 0.12 \mathrm{SE}$,

307 chemical cues: $2.27 \pm 0.15 \mathrm{SE}$ and for control: $2.39 \pm 0.19 \mathrm{SE})$. In males, no clear response in

308 activity could be detected, neither an overall response nor any difference between the treatments.

309

310 Heart rate

311 During the first observation, there were no overall differences between treatments nor any

312 general change in heart rate over time ( $\mathrm{p}>0.1$ all cases). However, a significant interaction

313 between time and treatment was found, indicating that the change in heart rate over time differed

314 between treatments $\left(\mathrm{F}_{27,130}=1.613, \mathrm{p}=0.03\right.$; figure 5$)$. Fish in the visual/chemical and visual

315 treatment responded with bradycardia (decreasing heart rate) immediately after exposure (first 10

316 s interval), whereas heart rate in the chemical and control treatments remained unaffected. 
317 During the second observation, heart rate decreased over time $\left(\mathrm{F}_{9,288}=2.268, \mathrm{p}=0.018\right)$ after

318 exposure regardless of treatment ( $p>0.1$, figure 4). No significant differences were found at the 319 last observation $(\mathrm{p}>0.1)$.

320

321

322

323

324

325

326

327

328

329

330

331

332

333

334

335

336

At the first observation, there was also a significant interaction between time and $\operatorname{sex}\left(\mathrm{F}_{9,270}=1.920, \mathrm{p}=0.049\right)$, where males showed a bradycardic response after the exposure, a response that was lacking in females (figure 6).

\section{Discussion}

In this study, we found that a combination of chemical and visual exposure generally yielded a response in focal fish similar to that resulting from visual exposure alone. This finding suggests that within this context, visual cues are more important than chemical cues for recognizing and responding to individuals within a social hierarchy in rainbow trout. Both activity and physiological responses were generally immediate, occurring within $10 \mathrm{~s}$ following the first exposure. The position response was positive, with the focal fish moving closer to the dominant, most likely a type of inspection behavior (Dugatkin \& Godin 1992), whereas the change in activity was more subtle and less immediate. Fish exposed to both chemical and visual cues reduced their activity after the second and last exposure and, in addition, the general overall activity was lower at the last exposure. Similarly, the heart rate response was rapid during the first observation, where fish exposed to the combined visual/chemical and visual treatment responded with a bradycardia after the exposure. Hence, the extra information provided when adding chemical cues did not change the observed behavioral or physiological responses. 
The literature presents conflicting findings on the relative importance of visual and

341 chemical cues in fish. It is generally suggested that visual communication may be more accurate,

342 direct and reliable and, therefore, plays a larger role in individual recognition, which is crucial

343 for the establishment of social hierarchies. In contrast, chemical cues most likely occur in a more

344 diffuse context and will mix with chemicals originating from different individuals as well as

345 compounds originating from other species and various processes within the ecosystem (Bradbury

346 \& Vehrencamp 1998, McLennan 2003). Nevertheless, chemical signals have been found to be an

347 effective means of communication in a wide range of taxa in the contexts of predator avoidance

348 (Brönmark \& Hansson, 2000, Chivers et al. 2006, Dahl et al. 1998), foraging (Fine et al., 1977,

349 Hara, 1993, Ringler 1979, Glova et al. 1992) migration (Sorensen et al., 2005, Caprona, 1982),

350 shoaling (Wisenden et al.,2003), kin recognition (Brown \& Brown 1993, Griffiths et al., 2003)

351 and reproduction (Belanger et al. 2006, Diaz \& Thiel 2004). These are all examples of

352 communication in a context that does not require individual recognition.

353

Visual cues, however, may allow recognition of specific individuals and could,

354

therefore, be important for assessing and remembering the competitive ability of conspecifics,

355

356

357

358

359

360

361

362

thereby avoiding costly conflicts in which the probability of winning is low (Enquist \& Leimar

1983; Johnsson \& Åkerman 1998). It is well known that subordinate salmonids darken during social interactions (Keenleyside \&Yakamoto 1962), a response that is believed to act as a signal modifying social behavior, thus reducing costly interactions. Similarly, dominant individuals within a species (this study, Keenleyside \&Yakamoto 1962, Höjesjö et al. 1998, Höjesjö et al. 2007) generally signal their superior status with erect fins and brighter coloration (O'Connor et

al. 1999). Smith \& Belk (2001) have suggested that during more risky behaviors such as predator inspection, mosquitofish (Gambusia affinis) rely mainly on visual cues, whereas general

PeerJ reviewing PDF | (2014:12:3481:2:0:NEW 8 Jul 2015) 
363 avoidance behavior is determined by additive responses from visual and chemical cues. This

364 generalization is supported by the findings of our study. We found that a visual stimulus from a

365 dominant conspecific causes a larger response in the subordinate focal fish and that no additive

366 response of the chemical stimuli could be detected. Alternatively, the subordinate individual

367 might not have had the opportunity to learn the chemical cues of a specific dominant within the

368 given time frame. In addition, dyadic and focal testing was conducted in relatively small tanks,

369 and this close proximity might result in a 'magnification' of the relative value of visual

370 information. Hence, in a more realistic natural environment, chemical cues may function as a

371 first cue that can alert the receiver to the presence of a second visual cue, thereby increasing the

372 probability of detection and recognition by the receiver (e.g. Smith \& Belk 2001). There are

373 several examples from various taxa suggesting that chemical cues are less species- and/or

374 individual-specific compared with visual cues and may not transfer the same amount of

375 information but may be used complementarily in the field (McLennan 2003, Kim et al. 09,

376 Palaoro et al. 2013) and may be used to enhance the accuracy with which receivers assess a

377 single quality (e.g., Johnstone et al. 1996). However, Brown and Magnavacca (2003) suggest

378 that chemical cues, in the form of prey alarm cues in the diet of the predator, are the primary

379 source of information regarding local predation risk during inspection behavior and that visual

380 cues are used if chemical information is unavailable or ambiguous. Bro-Jörgensen (2010) very

381 nicely illustrates how dynamic selection, in a fluctuating ecological and social environment, can

382 explain why multiple signals can be used to convey a message. Although visual cues are shown

383 to be more important in this study, information transfer between individuals may, of course, be

384 context dependent; in other situations, such as those involving reduced visibility, chemical cues

385 may play a larger and/or additive role. In a natural river, chemically mediated cues might also be 
more predictable and mainly orientated according to a unidirectional flow from an upstream source.

In agreement with previous studies, our data verify that the behavioral and physiological (change in heart rate) responses are linked (Höjesjö et al. 1999, Johnsson et al 2001). The physiological response of the focal fish also suggests that the information is mediated primarily by visual cues, at least in the short time frame, when the focal fish expressed a bradycardiac response. In a previous study (Höjesjö et al. 2007), the overall heart rate increased for focal fish sharing water with a superior contestant after $24 \mathrm{~h}$, whereas no such difference could be detected in the current study. In the current study, however, the chemical cues associated with the dominant fish were separated from the subordinate fish. Nevertheless, only the combination of chemical and visual cues or the visual cue alone resulted in the observed bradycardiac response, suggesting that visual cues are also the most important for generating a physiological response.

The more delayed tachycardic response found in the previous study cited above most likely arose from the more permanent chemical cues associated with the presence of a dominant opponent or a combination of initial visual cues and subsequent continuous exposure to chemical cues. Physiological responses towards stress such as the presence of a dominant individual are relatively well documented in teleost fish (see reviews by Pickering \& Pottering 1995), and the initial response can be a first rapid bradycardia mediated via the vagal innervation of the heart; this response then reverses and become tachycardia. The physiological significance of fright bradycardia has been discussed since it was first described by Belkin in 1968. It is well known that the electric signals that are generated by active muscles in the fish "leak" out in the water (Kalmijn 1974; 1988), and this electric profile can be used by a predator to locate prey 
409 (Wueringer et al. 2012). Moreover, alteration of the electric profile can be used to avoid the

410 predator (Kempster et al. 2013). The initial rapid bradycardia observed in this study could be an

411 attempt by the subordinate to mask itself electrically in the water and thereby avoid interaction

412 with the dominant individual.

This study also demonstrates differences between sexes in the response. Females

414

415

416

417

418

419

420

421

422

423

424

425

426

427

428

429

430

431

generally acted more bold (moved closer to opponents) and were more active when presented with the combined chemical and visual cue but not with the visual cue alone. Hence, there seemed to be an additive but sex-specific effect of visual and chemical cues, as each of the cues alone did not cause any change in position or activity in females. The bradycardiac response at the first observation when fish were exposed to a combined exposure of visual and chemical cues was also more pronounced in females. This result is somewhat surprising as juvenile male rainbow trout have previously been found to be more aggressive than females (Johnsson \& Åkerman 1998), and similar sex-specific aggression patterns have been reported in brown trout, where males also tend to be more bold than females (Johnsson et al. 2001). Similarly, Cooke (2004) detected that nesting males of largemouth bass had higher resting cardiovascular rates relative to non-nesting males and females, most likely linked to aggressive nest defense by males, which is critical for brood survival in this species (Sutter et al. 2012). The boldness detected in the females in our study could alternatively be interpreted as a form of inspection behavior (Dugatkin \& Godin 1992; Brown and Magnavacca 2003) whose overall function would be to avoid costly conflicts in which the probability of winning was low (Enquist \& Leimar 1983). These results are somewhat contradictory to the findings of our previous study (Höjesjö et al. 2007), where male bystanders moved closer to opponents prior to any information on the opponents' competitive ability. Juvenile sex differences in behavior may be favored as a 
432 correlated response to sexually selected genes in adult males and females during reproduction

433 (Cheverud et al. 1983; Bakker 1994). The present finding is, to our knowledge, one of the few in

434 juvenile fish suggesting that females are more bold and active than males, and the matter needs

435 to be further investigated.

436 In summary, the subordinate fish in our study showed similar behavioral and heart

437 rate responses to a combination of chemical and visual exposure and visual exposure alone,

438 suggesting that visual cues are more important than chemically mediated ones during the

439 formation and stabilization of social hierarchies in rainbow trout. To our knowledge, this is the

440 first study that has evaluated both behavioral and physiological responses in subordinate fish

441 exposed to both visual and chemical stimuli in a controlled experiment.

442

443 Acknowledgements

444

J. H. and J. I. J. were financed by the Swedish Research Council for Environment, 
453

454

455

456

457

458

459

460

461

462

463

464

465

466

467

468

469

470

471

472

473

474

475

\section{References}

Aeschlimann PB, Haberli MA, Reusch TBH, Boehm T, Milinski M. 2003. Female sticklebacks

Gasterosteus aculeatus use self-reference to optimize MHC allele number during mate selection.

Behav Ecol Sociobiol. 54:119-126.

Abbott JC \& Dill LM (1985): Patterns of aggressive attack in juvenile steelhead trout (Salmo gairdneri). Can. J. Fish. Aquat. Sci. 42: 1702-1706

Alcock J (2005) The evolution of communication. Animal Behaviour, An Evolutionary Approach. Sinauer Associates, Inc, pp 275-314

Altimiras J, Larsen E (2000) Non-invasive recording of heart rate and ventilation rate in rainbow trout during rest and swimming. Fish go wireless! Journal of Fish Biology 57(1):197-209.

Atema J, Todd JH, Bardach, JE (1969) Olfaction and behavioral sophistication in fish. Olfaction and taste. (Ed. By Pfaffmann, C.) Rockfeller University press, New York, 3: 241-251.

Bakker TCM (1994) Evolution of aggressive behaviour in the threespine stickleback. In: The evolutionary biology of the threespine stickleback (Bell, M. \& Foster, S.A., eds). Oxford Scientific Publishers. Oxford, pp 345-380.

Bell, A. M., Hankison, S. J. \& Laskowski, K. L. 2009. The repeatability of behaviour: 
476

477

478

479

480

481

482

483

484

485

486

487

488

489

490

491

492

493

494

495

496

498

497 Chapman DW (1966) Food and space as regulators of salmonid populations in streams. The

a meta-analysis. Animal Behaviour, 77, 771-783.

Barata EN, Hubbard PC, Almeida OG, Miranda A, Canario AVM. 2007. Male urine signals social rank in the Mozambique tilapia (Oreochromis mossambicus). BMC Biol. 5:54.

Belkin DA (1968) Bradycardia in response to threat. American Zoologists, 8:775.

Biben, M (1998) Squirrel monkey play fighting: making the case for a cognitive training function of play. In: Animal Play (Ed. by M. Bekoff \& J. Byers), pp. 161-182. Cambridge:

Cambridge University Press.

Belanger RM, Moore PA (2006) The Use of the Major Chelae by Reproductive Male Crayfish (Orconectes rusticus) for Discrimination of Female Odours. Behaviour 143:713-731.

Brown GE, Brown JA (1993a) Do kin always make better neighbours? The effects of territory quality. Behavioral Ecology and Sociobiology 33:225-231.

Brown GE, Magnavacca G (2003) Predator Inspection Behaviour in a Characin Fish: an interaction between Chemical and Visual Information? Ethology 109:739-750.

Brown GE, Brown JA (1993) Social dynamics in salmonid fish: do kin make better neighbours? Animal Behaviour 45: 863-871. American Naturalist 100:345-357. 
500 Cheverud JM, Rutledge JJ, Atchley WR (1983) Quantitative genetics of development: genetic

501 correlations among age specific trait values and the evolution of ontogeny. Evolution 37: 895502905.

503

504 Chivers DP, Smith RJF (1998) Chemical alarm signalling in aquatic predator-prey systems: A 505 review and prospectus. Ecoscience 5(3): 338-352.

507 Civers, DP, Puttlitz MH, Blaustein AR (2000) Chemical alarm signalling by reticulate sculpins, 508 Cottus perplexus. Environmental Biology of Fish 57: 347-352.

509

510 Clutton-Brock TH, Hodge SJ, Spong G, Russell AF, Jordan NR, Bennett NC, Sharpe LL, 511 Manser MB (2006) Intrasexual competition and sexual selection in cooperative mammals. 512 Nature 444 (21/28): 1065-1068.

514 Crapon de Caprona MD (1982) The influence of early experience on preferences for optical and 515 chemical cues produced by both sexes of a cichlid fish, Haplochromis burtoni. Zeitschrifter fur 516 tierpsychologie. Journal of comparative ethology 58: 329-361.

518 Dahl JP, Nilsson A, Pettersson LB (1998) Against the Flow: Chemical Detection of 519 Downstream Predators in Running Waters. Proceedings: Biological Sciences 265(1403) 22: $520 \quad 1339-1344$ 
522 Díaz ER, Thiel M (2004) Chemical and visual communication during mate searching in rock

523 shrimp. Biological Bulletin 206:134-143.

524

525 Dugatkin LA, Godin J-GJ (1992) Prey approaching predators: a cost-benefit perspective.

526 Annales Zoologici Fennici 29:233-252.

527

528 Dugatkin LA (1997) Winner effects, loser effects and the structure of dominance hierarchies.

529 Behavioral Ecology 8:583-587.

530

531 Dugatkin LA \& Druen M (2004): The social implications of winner and loser effects. Proc. R.

532 Soc. Lond. B 271, S488-S489

533

534 Enquist M, Leimar O (1983) Evolution of fighting behaviour; decision rules and assessment of 535 relative strength. Journal of Theoretical Biology 102:387-410.

536

537 Espmark Y, Langvatn R (1985) Development and habituation of cardiac and behavioural 538 responses in young reddeer calves (Cervus elaphus) exposed to alarm stimuli. Journal of 539 Mammalogy 66: 702-711.

540

541 Fine ML, Winn HE, Olla BL (1997) Communication in selected groups: communication in fish.

542 In: How animal communicate (Ed. Thomas A. Sebeok), Indiana University press, Bloomington 543 pp 472-518. 
545 Glova GJ, Sagar PM, Naslund I (1992) Interaction for food and space between populations of

546 Galaxias vulgaris Stokell and juvenile Salmo trutta L. in a New Zealand stream. Journal of Fish

547 Biology 41: 909-925.

548

549 Gonzalo A, Lo'pez P, Martin J (2007) Iberian green frog tadpoles may learn to recognize novel 550 predators from chemical alarm cues of conspecifics. Animal Behaviour 74:447-453.

553 Giske J, Huse G, Fiksen O. 1998. Modelling spatial dynamics of fish.

554 Rev Fish Biol Fish. 8:57-91.

555

556 Griffiths SW, Armstrong JD (2000) Differential responses of kin and non kin salmon to patterns 557 of water flow: does recirculation influence aggression. Animal Behaviour 59:1019-1023.

558

559 Griffiths SW, Armstrong JD, Metcalfe NB (2003) The cost of aggregation: juvenile salmon

560 avoid sharing winter refuges with siblings. Behavioural Ecology 14 (5):602-606.

561

562 Griffiths SW, Brockmark S, Höjesjö J, Johnsson JI (2004) Coping with divided attention: the 563 advantage of familiarity. Proceedings of the Royal Society B 271: 695-699.

564

565 Gurney WSC, Nisbet RM (1979) Ecological stability and social hierarchy. Theoretical

566 Population Biology 16:48-80. 
568 Guthrie DM, Muntz WRA (1993) Role of vision in fish behaviour. In: Behaviour of teleosts fish.

569 (Ed. By Tony J. Pitcher), Chapman \& Hall, London pp 89-128.

570

571 Hara TJ, (1993) Role of olfaction in fish behaviour. In: Behaviour of teleosts fish. (Ed. By Tony

572 J. Pitcher), Chapman \& Hall, London pp 171-199.

573

574 Hasler AD, Cooper JC. 1976. Chemical cues for homing salmon. Experientia.

$57532: 1091-1093$.

576

577 Huntingford FA, Turner AK (1987) Animal Conflict. London: Chapman \& Hall.

578

579 Huntingford FA, Metcalfe NB, Thorpe JE, Graham WD, Adams CE (1990) Social dominance

580 and body size in Atlantic salmon parr, Salmo salar L. Journal of fish biology 36:887-881.

581

582

583

Höjesjö J, Johnsson JI, Petersson E, Järvi T (1998) The importance of being familiar: individual recognition and social behaviour in sea trout (Salmo trutta). Behavioural Ecology 9: 445-451.

584

585

Höjesjö J, Johnsson JI, Axelsson M (1999) Behavioural and heart rate responses to food 586 limitation and predation risk: an experimental study on rainbow trout. Journal of fish biology $587 \quad 55: 1009-1019$. 
589

590

591

592

593

594

595

596

597

598

599

600

601

602

603

604

605 606

607

608

609

610 611 of Fish. Volume 24 Fish Physiology (Elsevier Inc).

Höjesjö J, Andersson P, Engman A, Johnsson JI (2007) Rapid bystander assessment of intrinsic fighting ability: behavioural and heart responses in rainbow trout. Animal Behaviour 74:17431751

Johnsson JI, Åkerman A (1998) Watch and learn: preview of the fighting ability of opponents alters contest behaviour in rainbow trout. Animal Behaviour 56:771-776.

Johnsson JI, Åkerman A (1998) Intersexual differences in aggression in juvenile rainbow trout. Journal of Fish Biology 52:1292-1294.

Johnsson JI, Höjesjö J, Fleming IA (2001) Behavioural and heart rate responses to predation risk in wild and domesticated Atlantic salmon. Canadian Journal of Fisheries and Aquaticic Sciences 58:788-794.

Johnsson JI, Kjällman-Eriksson K (2008) Cryptic prey colouration increases search time in brown trout (Salmo trutta): effects of learning and body size. Behavioral Ecology and Sociobiology 62:1613-1620.

Johnsson JI, Sernland E, Blixt M (2001) Sex-specific aggression and antipredator behaviour in young brown trout. Ethology 107:587-599.

610 Johnsson JI, Winberg S, Sloman KA (2006) Social interactions. In: Behaviour and Physiology 
613 Johnsson JI (1997) Individual recognition affects aggression and dominance relations in rainbow 614 trout, Oncorhynchus mykiss. Ethology 103:267-282.

615

616 Johnsson JI, Nöbbelin F, Bohlin T (1999) Territorial competition among wild brown trout fry: 617 effects of ownership and body size. Journal of Fish Biology 54:469-472.

618

619 Johnstone RA (1996) Multiple displays in animal communication: 'Backup signals' and 620 'multiple messages'. Phil. Trans. R. Soc. B 351:329-338.

621

622 Jordâo LC, Volpato GL (2000) Chemical transfer of warning information in non-injured fish. 623 Behaviour 137:681-690.

624

625

Bro-Jørgensen J (2010) Dynamics of multiple signalling systems: animal communication in a 626 world in flux. Trends in Ecology and Evolution 25(5):292-300.

627

628

Kalmijn AJ (1988) Detection of Weak Electric Fields. In: Sensory Biology of Aquatic Animals

629 pp 151-186.

630

631 Kalmijn AJ (1974) The Detection of Electric Fields from Inanimate and Animate Sources Other

632 Than Electric Organs. In: Electroreceptors and Other Specialized Receptors in Lower

633 Vertebrates. Handbook of Sensory Physiology Volume 3 / 3:147-200.

634 
635 Kempster R-M, Hart NS, Collin SP (2013) Survival of the Stillest: Predator Avoidance in Shark

636 Embryos. PLoS ONE 8(1): e52551. doi:10.1371/ journal.pone.0052551

637

638 Keenleyside MA, Yakamoto FT (1962) Territorial behaviour in juvenile Atlantic salmon (Salmo 639 salar). Behaviour 19:139-169.

640

641 Kim J-W, Brown GE, Dolinsek IJ, Brodeur NN, Leduc AOH, Grant JWA (2009) Combined

642 effects of chemical and visual information in eliciting antipredator behaviour in juvenile Atlantic

643 salmon Salmo salar. Journal of Fish Biology 74:1280-1290.

644

645 Martel G, Dill LM (1993) Feeding and aggressive behaviours in juvenile coho salmon

646 (Oncorhynchus kisutchu) under chemically-mediated risk of predation. Behavioral Ecology and

647 Sociobiology 32:365-370.

648

649 McLennan DA (2003) The importance of olfactory signals in the gasterosteid

650 mating system: sticklebacks go multimodal. Biological Journal of the Linnean Society 80: 555-

651572.

652

653 McGhe KE, Travis J (2010): Repeatable behavioural type and stable dominance rank in the

654 bluefin killifish Animal Behaviour 79, 497-507

655

656 Maynard SJ (1974) The theory of games and the evolution of animal conflicts. Journal of

657 theoretical biology 47:209-221. 
659 Maynard SJ, Parker GA (1976) The logic of asymmetric contests. Animal Behaviour 24:159-

660175.

661

662 McGregor KP, Peake MT (2000) Communication networks: social environments for receiving 663 and signalling behaviour. Acta ethol 2:71-81.

664

665

Moen AN, Dellfera AL, Hiller AL, Buxton BA (1978) Heart rates of white tailed deer fawns in response to recorded wolf howls. Canadian Journal of Zoology 56:1207-1210.

667

668

Neat FC, Taylor AC, Huntingford FA (1998) Proximate costs of fighting in male cichlid fish: the 669 role of injuries and energy metabolism. Animal Behaviour 55: 875-882.

670

671

O'Connor KI, Metcalfe NB, Taylor AC (2000) Familiarity influences body darkening in territorial disputes between juvenile salmon. Animal Behaviour 59:1095-1101.

673

O'Connor KI, Metcalfe NB, Taylor AC (1999) Does darkening signal submission in territorial 675 contests between Atlantic salmon, Salmo salar? Animal Behaviour 58:1269-1276.

676

677 Oliveira RF, McGregor PK, Latruffe C (1998) Know thine enemy: fighting fish gather 678 information from observing conspecifics interactions. Proceedings of the Royal Society B. $679265: 1045-1049$.

680 
681 Parker GA (1974) Assessment strategy and the evolution of animal conflicts. J. Theor. Biol. 47, $682 \quad 223-243$.

683

684 Palaoro AV, Ayres-Peres L, Santos S (2013) Modulation of male aggressiveness through 685 different communication pathways. Behavioral Ecology and Sociobiology 67:283-292.

686

687 Pickering AD, Pottering TG (1995) Biochemical effects of stress. In: Biochemistry and 688 Molecular Biology of Fish. (Ed. by: P.W. Hochachka \& T.G. Pottinger) Vol. 5:349-379. 689 Elsevier, Amsterdam.

690

691 Pitcher TJ (1993) Behaviour of teleost fish, Second edition. Chapman \& Hall, pp 85-88.

692

693 Porter RH, Matochik JA, Makin JW (1986) Discrimination between full-sibling spiny mice 694 (Acomys cahirinus) by olfactory signatures. Animal Behaviour 34:1182-1188.

695

696

697

698

699 temperament within ecology and evolution, Biol. Rev, 82, pp. 291-318.

700

701

Quinn TP, Dittman AH (1990) Pacific Salmon Migrations and Homing: Mechanisms and 702 Adaptive Significance. Trends in Ecology and Evolution 5(6):174-177. 
704

705

706

707

708

709

710

711

712

713

714

715

716

717

718

719

720

721

722

723

724

725

726

Rosenthal GG, Lobel PS (2006) Communication. Fish Physiology 24:39-78.

Schuett G (1997) Body size and agonistic experience affect dominance and mating success in male copperheads. Animal Behaviour 54:213-224.

Sloman KA, Armstrong JD (2002) Physiological effects of dominance hierarchies: laboratory artefacts or natural phenomena? Journal of Fish Biology 61:1-23.

Smith ME, Belk MC (2001) Risk Assessment in Western Mosquitofish (Gambusia affinis): Do Multiple Cues Have Additive Effects? Behavioral Ecology and Sociobiology 51(1):101-107.

Sorensen PW, Scott AP (1994) The evolution of hormonal sex pheromones in teleost fish: Poor correlation between the pattern of steroid release by goldfish and olfactory sensitivity suggests that these cues evolved as a result of chemical spying rather than signal specialisation. Acta Physiol. Scand. 152:191-205.

Tubert C, Lo-Nostro F,Villafañe V, Pandolfi M (2012) Aggressive behavior and reproductive physiology in females of the social cichlid fish Cichlasoma dimerus. Physiology \& Behavior 106:193-200.

Ward AJW, Axford S, Krause J. 2002. Mixed-species shoaling in fish:the sensory mechanisms and costs of shoal choice. Behav Ecol Sociobiol. 52:182-187.

Webster MM, Goldsmith J, Ward AJW, Hart PJB. 2007. Habitat-specific

chemical cues influence association preferences and shoal cohesion 
727 in fish. Behav Ecol Sociobiol. 62:273-280.

728

729 Valentincic T, Caprio J (1997) Visual and chemical release of feeding behaviour in adult

730 rainbow trout. Chemical senses 22:375-382.

731

732 Pottinger T (2007) Stress and stress coping in fish, behavioural correlates and neuroendocrine

733 mechanisms. Comparative Biochemistry and Physiology Part A: Molecular \& Integrative

734 Physiology Suppl. 4s 1: 146.

735 Wisenden BD, Pollock MS, Tremaine RJ, Webb JM, Wismer ME, Chivers DP (2003)

736 Synergistic interactions between chemical alarm cues and the presence of conspecific and

737 heterospecific fish shoals. Behavioral Ecology and Sociobiology 54:485-490.

738

739 Wueringer BE, Squire L Jnr, Kajiura SM, Tibbetts IR, Hart NS (2012) Electric Field Detection

740 in Sawfish and Shovelnose Rays. PLoS ONE 7(7): e416

741 05. doi:10.1371/journal.pone.0041605.

742

743

744

745 


\section{1}

Figure 1

An illustration of the four different treatments used in the study. The subordinate fish (S), our focal fish, is always positioned in the front section, and the dominant (D) is positioned in the back or in a separate aquarium to expose the focal fish only to chemical cues. Visual and chemical cues could be separated through the use of the hatch either separately or in combination with the hose pumping water into the front tank. The chemical cue was always introduced along the longside in the front tank facing the other aquarium in order to standardize the source of the cue.

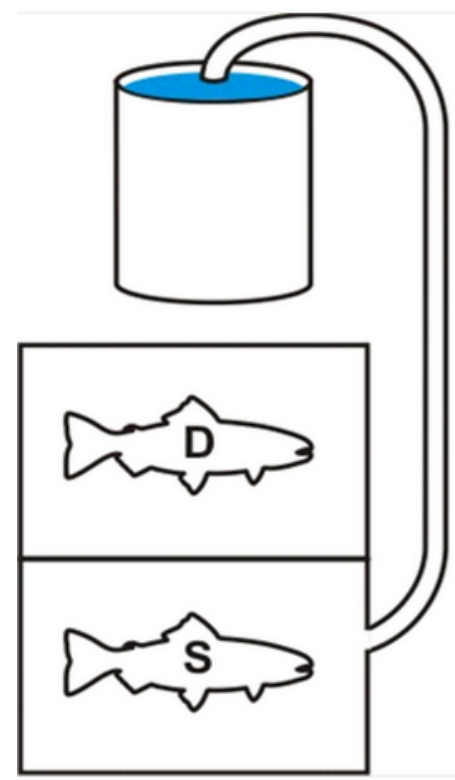

Visual (V)

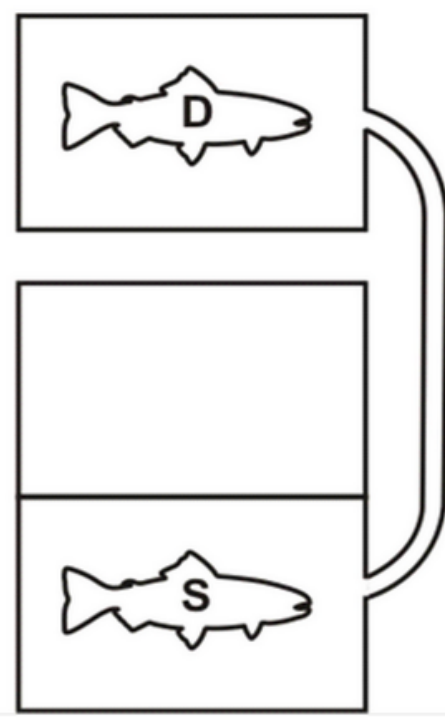

Chemically $(\mathrm{Ch})$

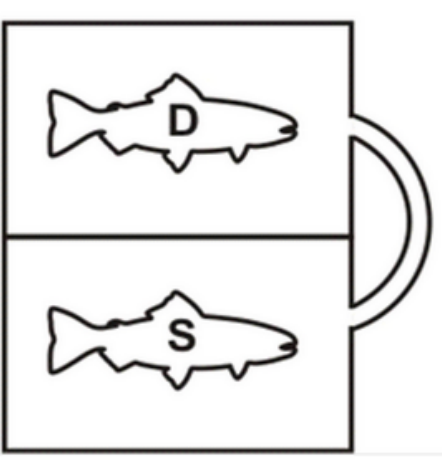

Chemically + Visual (ChV)

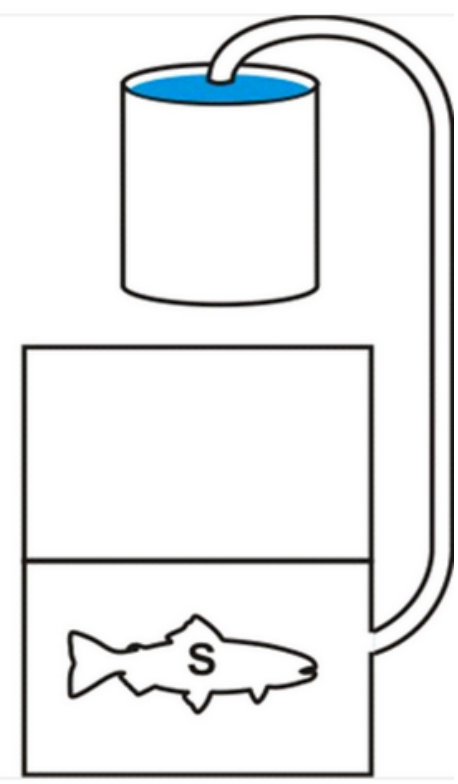

Control (Co) 
2

Fig 2

The change in position of the subordinate fish during the first (a), second (b) and last (c) observation for the different treatments ( $C h V=C h e m i c a l$ and Visual, $\mathrm{V}=\mathrm{Visual}, \mathrm{Ch}=\mathrm{Chemical}$ and $\mathrm{Co}=\mathrm{Control})$. The dotted line refers to the time of exposure. Error bars denote the standard error of the group means. Here, only positive values of the standard error are presented. 

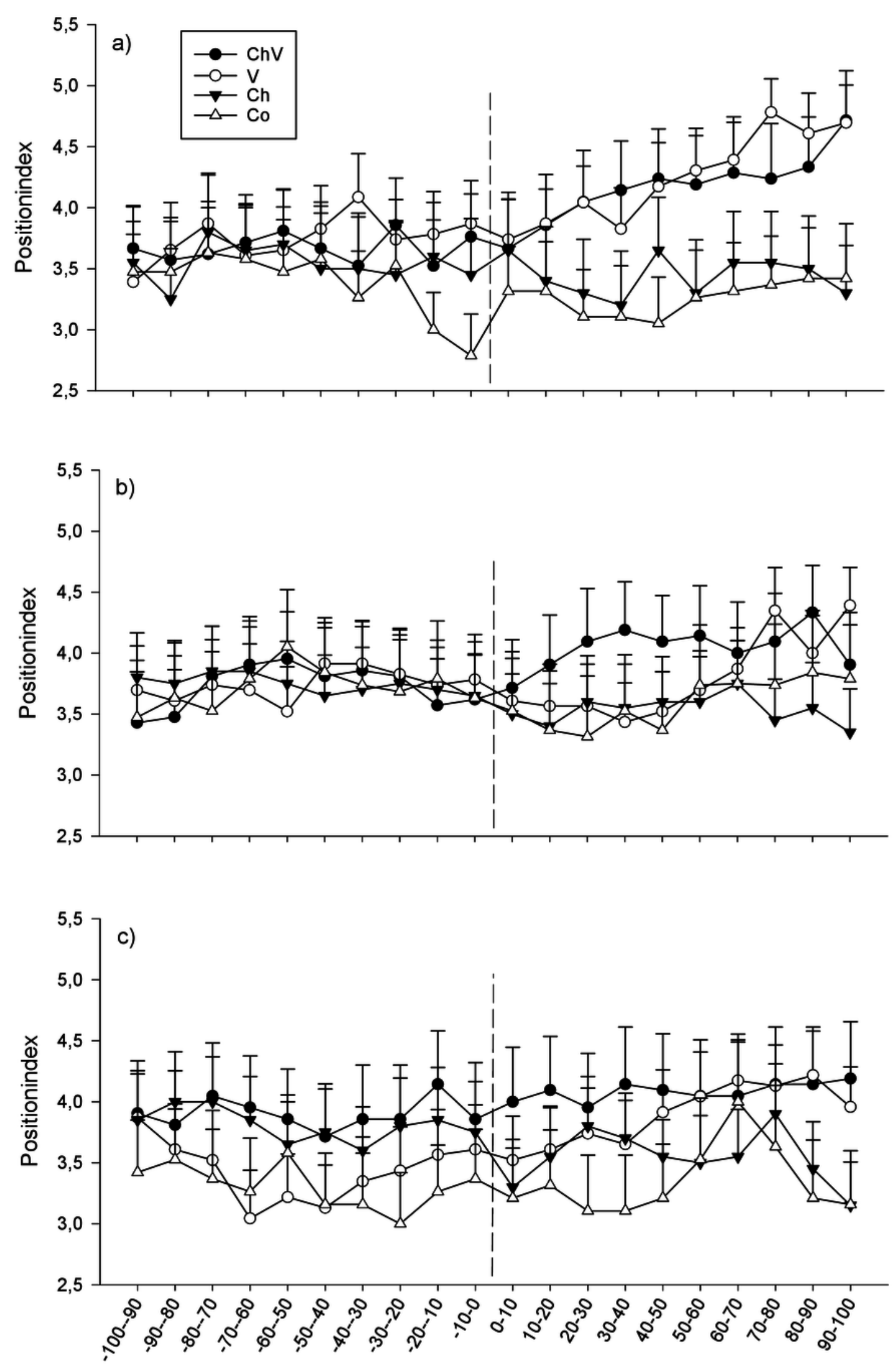

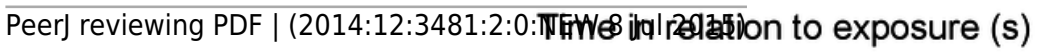


3

Fig 3

The difference between sexes in the position index for fish exposed to both visual and chemical cues (chemical + visual treatment) during the second observation. The dotted line refers to the time of exposure. Error bars denote the standard error of the group means. Here, only positive values ofthe standard error are presented. 


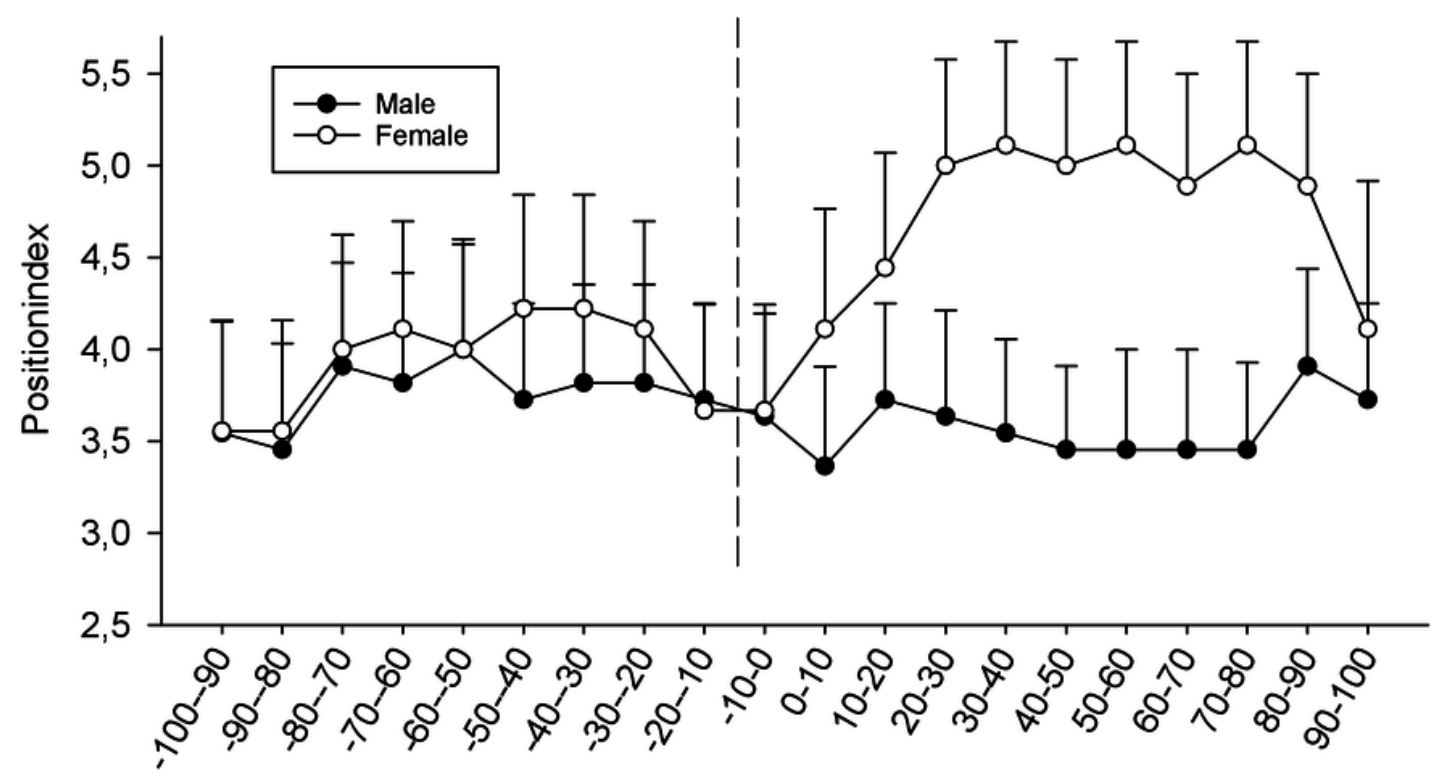

Time in relation to exposure (s) 
4

Fig 4

The change in activity of the subordinate fish during the first (a), second (b) and last (c) observation for the different treatments ( $\mathrm{ChV}=\mathrm{Chemical}$ and Visual, $\mathrm{V}=\mathrm{Visual}, \mathrm{Ch}=\mathrm{Chemical}$ and $\mathrm{Co}=$ Control). The dotted line refers to the time of exposure. Error bars denote the standard error of group means. Here, only positive values of the standard error are presented. 

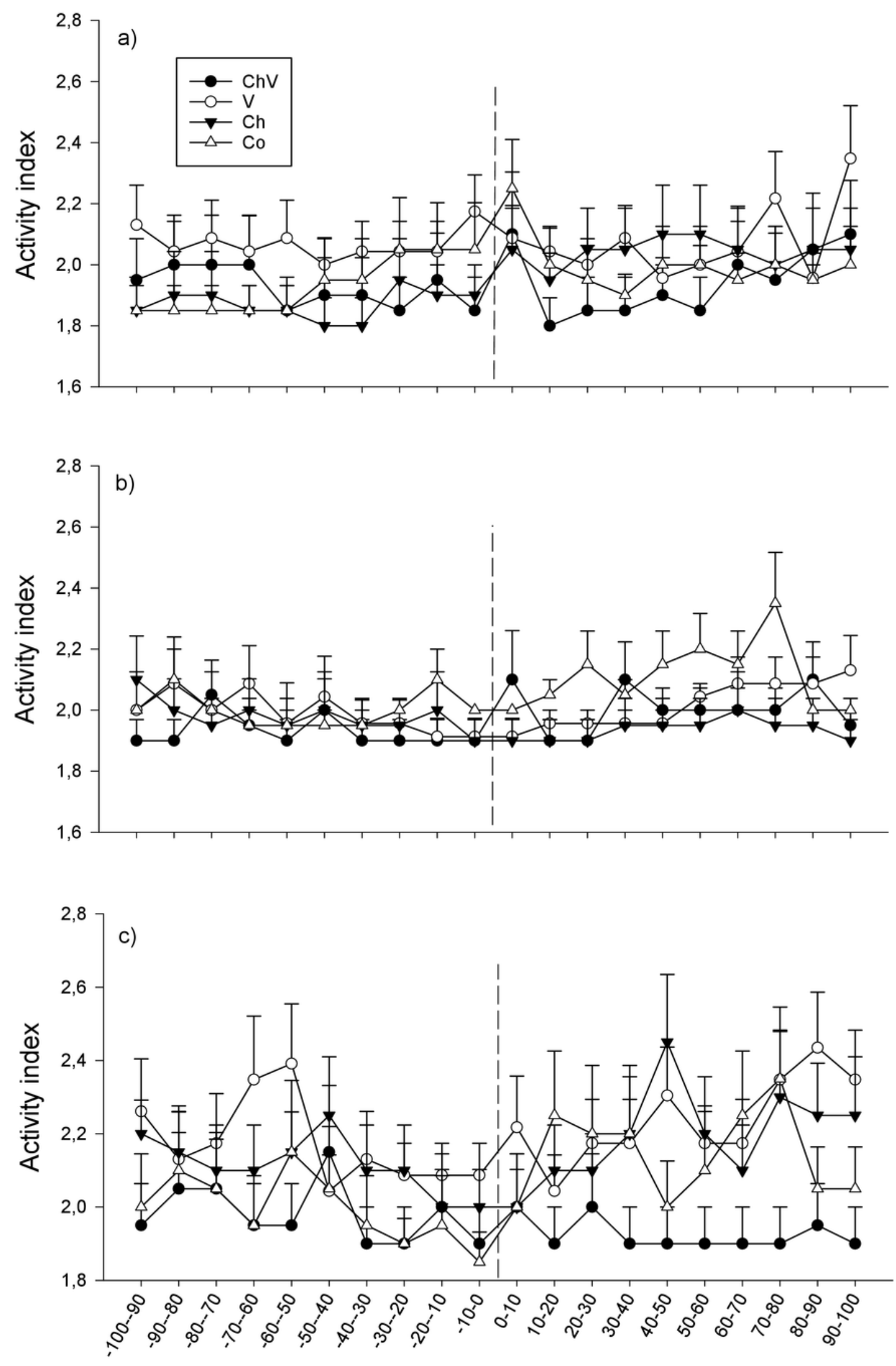

Time in relation to exposure (s) 


\section{5}

Fig 5

The average change in heart rate $( \pm S E)$ of the subordinate fish during the first (a), second (b) and last (c) observation for the different treatments ( $C h V=C h e m i c a l$ and Visual, $\mathrm{V}=\mathrm{Visual}$, $\mathrm{Ch}=$ Chemical and $\mathrm{Co}=\mathrm{Control})$. The dotted line refers to the time of exposure. Error bars denote the standard error of group means. Here, only positive values of the standard error are presented. 

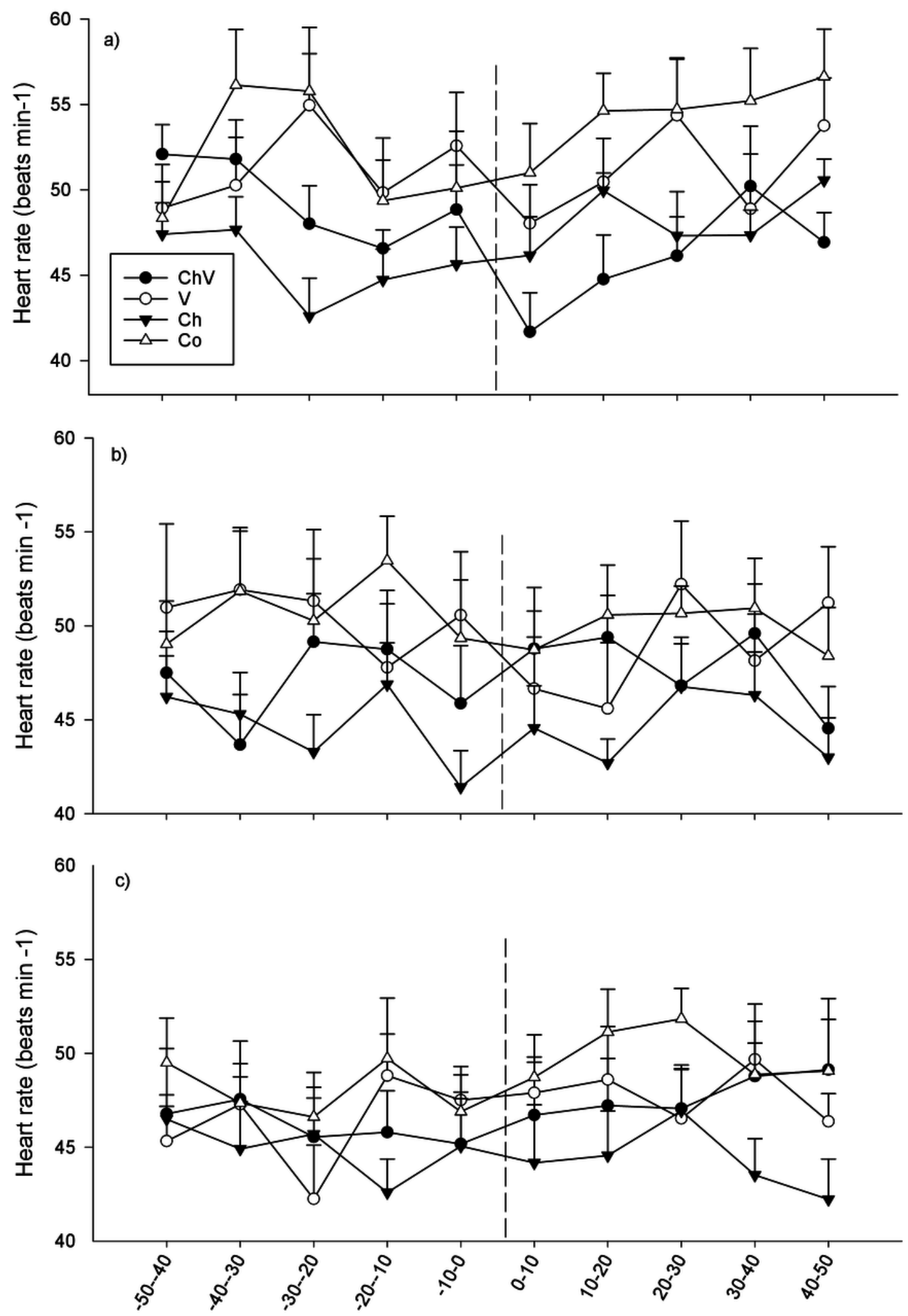

Time in relation to exposure (s) 
6

Fig 6

The overall difference in heart rate response between sexes during the first observation. The dotted line refers to the time of exposure. Error bars denote the standard error of the group means, Here, only positive valuesof the standard error are presented. 


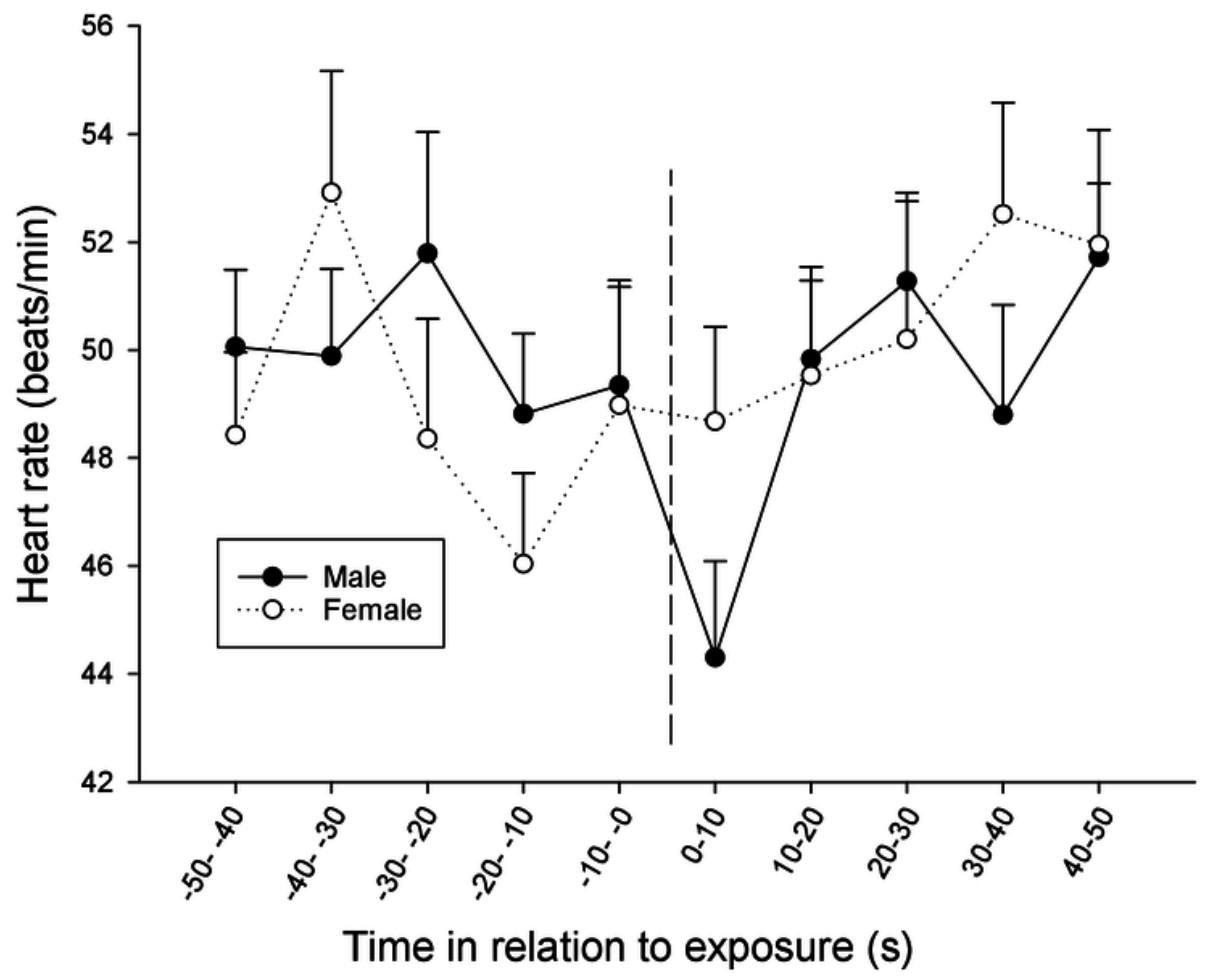

